\title{
A Technique for Restoring Severely Resorbed Edentulous Mandible with a Computer-aided Design and Computer-aided Manufacturing Surgical Guide and an Implant-supported Fixed Dental Prosthesis in Two Days
}

\author{
Ilser Turkyilmaz ${ }^{1}$, Sila C Isler ${ }^{2}$, Ahu Uraz ${ }^{3}$
}

\begin{abstract}
Aim: The aim of this report is to describe a technique, in which a severely resorbed edentulous mandible was restored with computer-aided design/computer-aided manufacturing (CAD/CAM) surgical guide and an implant-supported fixed dental prosthesis in two days.

Background: The quality of life of edentulous patients is generally restricted due to functional and psychosocial problems associated with complete dentures. These issues become worse over time due to ongoing bone resorption. Implant-supported prostheses have been utilized to overcome these problems.

Case description: A 79-year-old patient with a severely resorbed edentulous maxilla and mandible presented to our clinic. After the cone beam computed tomography (CBCT) scans were performed, five implants were virtually placed via a 3-dimensional software. Then, a CAD/CAM surgical guide was fabricated with a stereolithographic method. Her mandible was restored with five implants by using the CAD/CAM surgical guide and the implant-supported prosthesis with CAD/CAM titanium framework in 2 days.

Conclusion: The severely resorbed edentulous mandible was successfully restored with five dental implants, and the implant-supported fixed dental prosthesis via the CAD/CAM milled titanium framework.

Clinical significance: The technique using software and hardware portrayed in this report may be a feasible option to restore similar patients if it is executed by trained restorative dentists adhering to strict guidelines.

Keywords: Computer-aided design/computer-aided manufacturing, Cone beam computed tomography, Implant, Mandible, Surgical guide The Journal of Contemporary Dental Practice (2019): 10.5005/jp-journals-10024-2550
\end{abstract}

\section{INTRODUCTION}

$M$ ost edentulous patients using complete dentures suffer from functional, esthetic, and psychosocial problems. ${ }^{1-3}$ Some patients with extremely resorbed mandibles report intensive electric shock-like pain during eating as the mental foramina are located on the alveolar crest, therefore, the mental nerve is crushed between the alveolar bone and the denture base. Implantsupported fixed dental prostheses (FDP) are utilized to overcome those issues. ${ }^{2}$ However, in today's world, the long waiting period for osseointegration and several appointments for prostheses are not easily accepted by patients.

Dentistry has recently been influenced by several digital technologies such as cone-beam computed tomography (CBCT), computer-aided design and computer-aided manufacturing (CAD/ CAM), stereolithography (SLA), and 3-dimensional (3D) implant planning software for virtual implant treatment planning. ${ }^{4-11}$ These advancements have already changed the way we treat our patients, providing better outcomes in shorter periods of time. . $^{4-6}$

The goals of this clinical report are to illustrate the technique, in which a severely resorbed edentulous mandible was rehabilitated with a CAD/CAM surgical guide and an implant-supported fixed dental prosthesis in two days, and to present the 2 -year outcomes of this patient.

\section{Case description}

A 79-year-old female patient with severely resorbed edentulous maxilla and mandible was presented to our faculty practice. She stated that she had been using complete dentures about 35 years, and also had
${ }^{1}$ Department of Prosthodontics, New York University College of Dentistry, , New York, NY, USA

${ }^{2,3}$ Department of Periodontology, Faculty of Dentistry, Gazi University, Ankara, Turkey

Corresponding Author: Ilser Turkyilmaz, Department of Prosthodontics, New York University College of Dentistry, , New York, NY, USA, Phone: +1-212-992-7181, e-mail: ilserturkyilmaz@yahoo.com

How to cite this article: Turkyilmaz I, Isler SC,Uraz A. A Technique for Restoring Severely Resorbed Edentulous Mandible with a Computeraided Design and Computer-aided Manufacturing Surgical Guide and an Implant-supported Fixed Dental Prosthesis in Two Days. J Contemp Dent Pract 2019;20(4):524-528.

Source of support: Nil

Conflict of interest: None

been having electric shock-like pain in the mandible while eating for 5 years; therefore she desired an implant-supported FDPas soon as possible. Because certain levels of deviations from the digital plan to the surgical field were reported, some clinicians tend to plan implants away from the nerve. The close proximity of the distal implant locations to the mental nerves and insertion of the definitive prosthesis using CAD/CAM titanium frameworks in two days are the main differences between the present case and the cases in other reports.

\section{Day 1}

The patient signed informed consent before the surgery. The existing mandibular denture was converted to a radiographic guide after incorporating fiducial markers. Then, it was placed into

() The Author(s). 2019 Open Access This article is distributed under the terms of the Creative Commons Attribution 4.0 International License (https://creativecommons. org/licenses/by-nc/4.0/), which permits unrestricted use, distribution, and non-commercial reproduction in any medium, provided you give appropriate credit to the original author(s) and the source, provide a link to the Creative Commons license, and indicate if changes were made. The Creative Commons Public Domain Dedication waiver (http://creativecommons.org/publicdomain/zero/1.0/) applies to the data made available in this article, unless otherwise stated. 
the mouth with an accurate bite-registration record, and the first CBCT scan was obtained. The second CBCT scan was acquired after placing the radiographic guide on the scanning table of the $\mathrm{CBCT}$ machine. Five implants were virtually designed according to the final prosthesis (Nobel Clinician, Nobelbio care, Yorba Linda, CA) (Fig. 1), and the surgical guide is fabricated by using a CAD/CAM method (Nobel Forte, Nobelbiocare, Yorba Linda, CA).

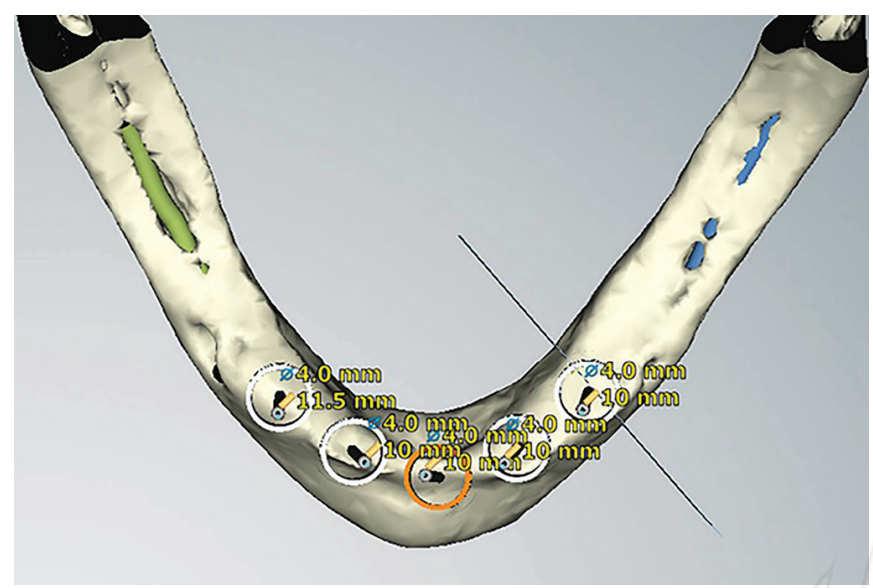

Fig. 1: Occlusal view after five implants were virtually placed

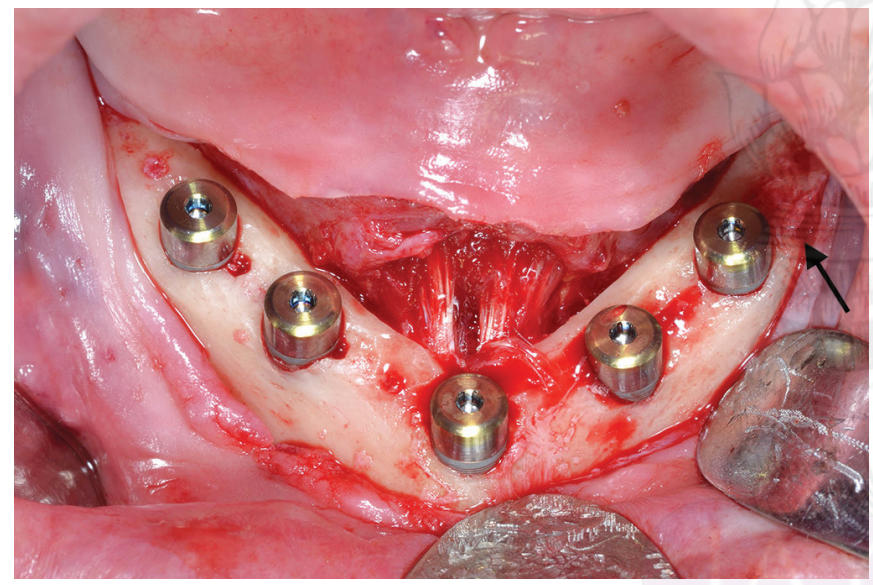

Fig. 2: Intraoral view of the patient immediately after implant placement. Note minimum distance between left distal implant, and foramen mentalis and mental nerve

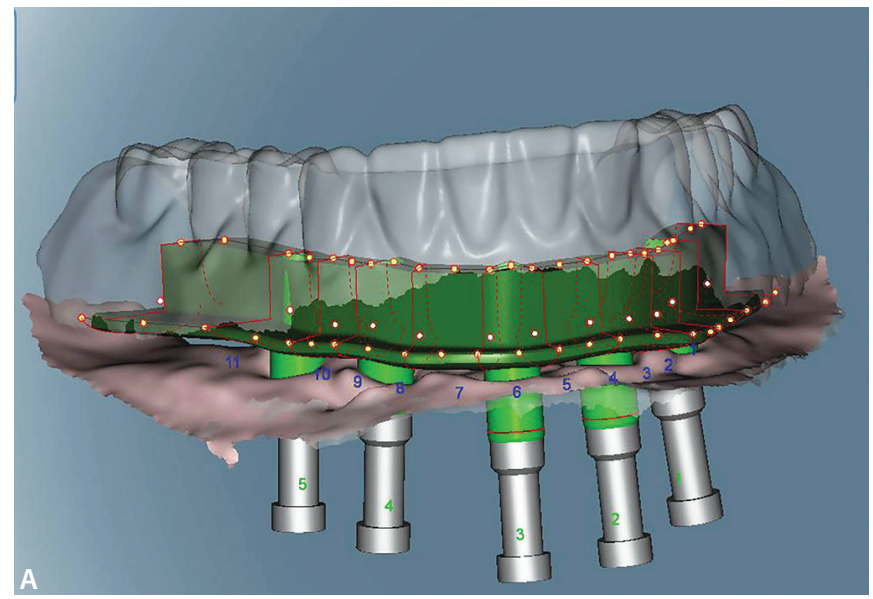

After the CAD/CAM surgical guide was seated in the mouth, the implant sockets were prepared, and then five implants $(4 \times$ $10 \mathrm{~mm}$, Nobel Replace Groovy, Nobel Biocare, Yorba Linda, CA) were placed through the metal sleeves in the surgical guide (Nobel Guide, Nobel Biocare, Yorba Linda, CA). A soft tissue flap was elevated because it was crucial to visualize both the mental foramina and the nerve as the implants were placed very close to them (Fig. 2) and to maintain keratinized soft tissue around the implants.

The steps below were followed to fabricate the implantsupported screw-retained FPD. A final impression using a polyvinyl siloxane impression material (Aquasil, Dentsply Intl, York, PA)was made immediately after the soft tissue closure. Implant replicas were attached to the impression copings, and the definitive cast was made (Resin Rock, Whip Mix Corp, Louisville, KY). Three scanning procedures (the definitive cast with and without scanning abutments, and trial denture) were performed accurately (Figs 3 and 4), then the 3D planning software superimposed these three different scans without any problems. Based on the scan of the trial denture, contour and dimension of the framework were determined. The final design was sent electronically to the production center, where the complete-arch titanium framework was milled from a titanium block in the same day (Fig. 5).

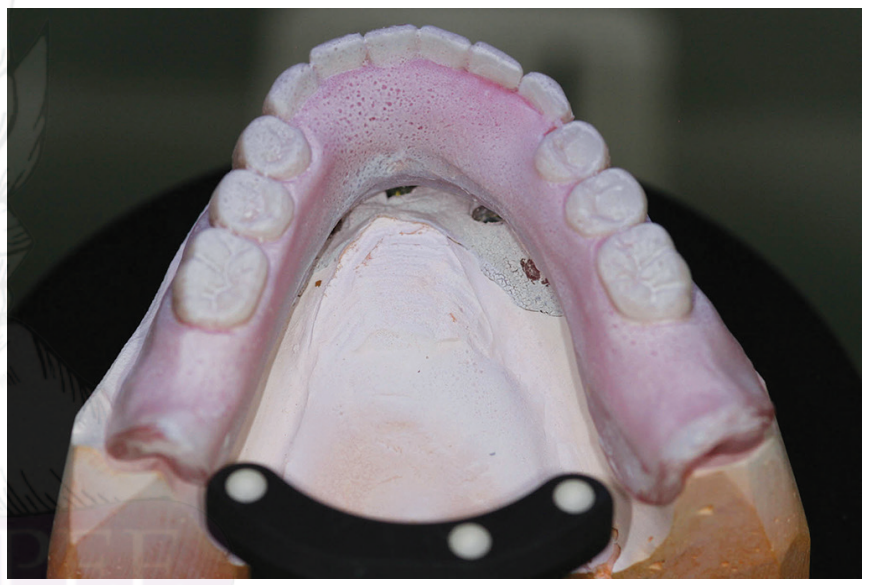

Fig. 3: Occlusal view of the trial denture before scanning in order to determine the design of the framework

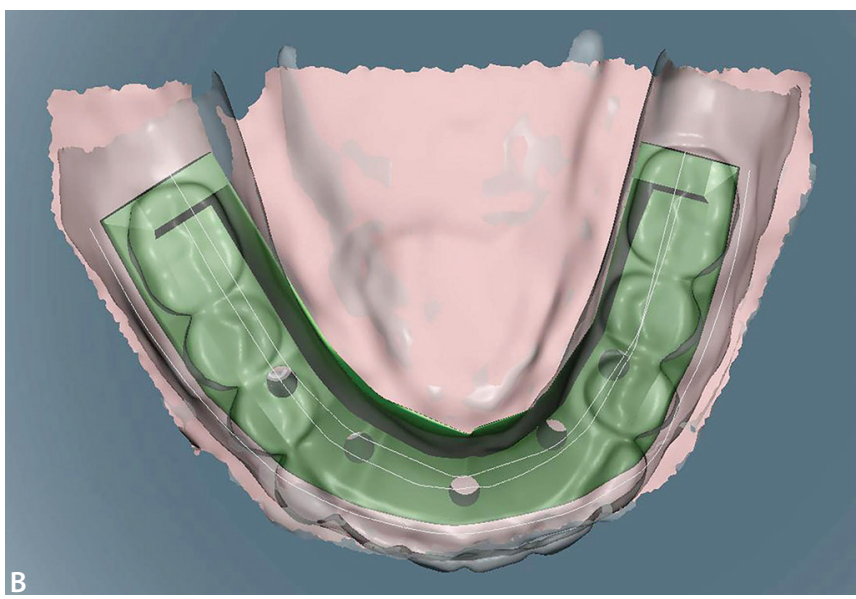

Figs 4A and B: Frontal (A) and occlusal; (B) views of the final design of the framework according to the positions of the implants and denture teeth 


\section{Day 2}

After the intraoral fit of the CAD/CAM titanium framework was verified, the denture teeth (Ivoclar Vivadent Inc, Amherst, NY) were transferred from the trial denture onto the framework. The centric occlusion, esthetics, phonetics, and occlusal vertical dimension were confirmed. In the afternoon, the implant-supported screwretained FPD was processed, finished, and polished in the laboratory

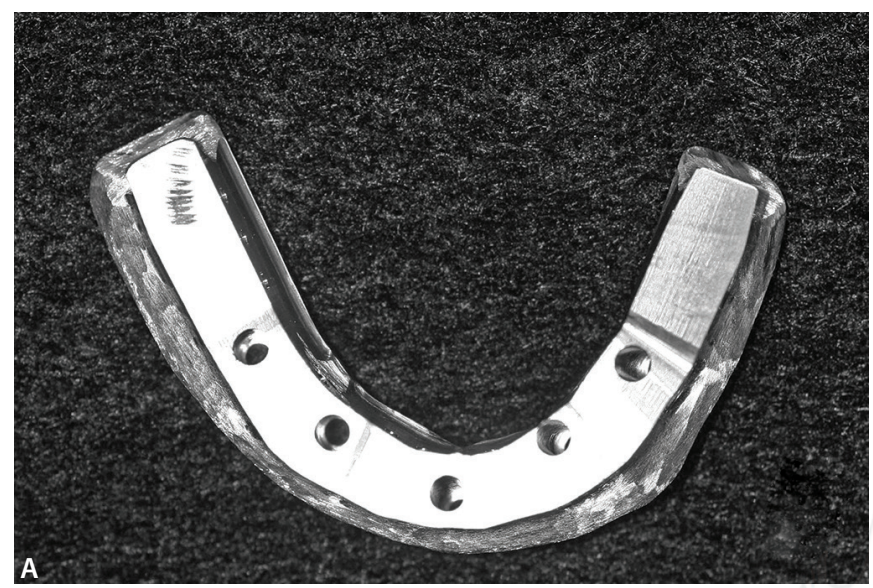

Figs $5 \mathrm{~A}$ and $\mathrm{B}$ : Occlusal $(\mathrm{A})$ and intra-oral. (B) views of the fabricated framework

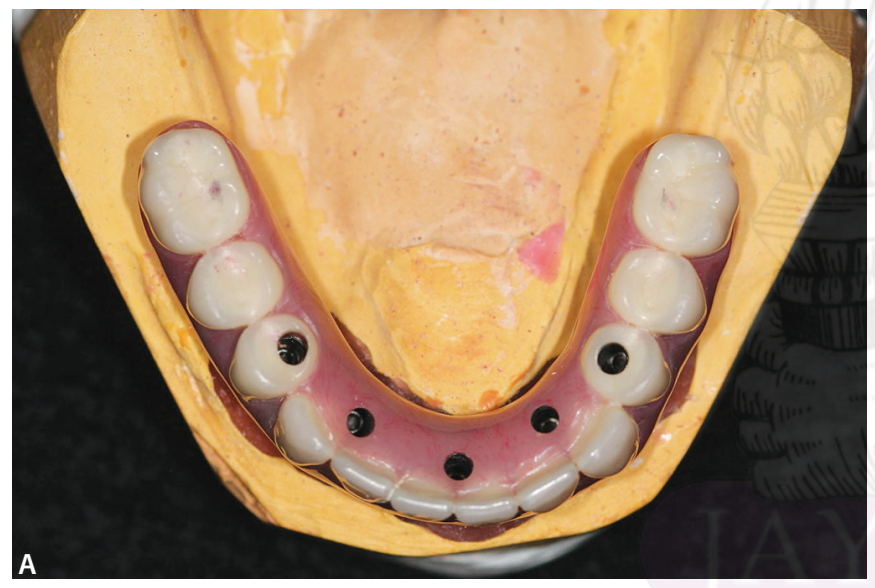

Figs $6 \mathrm{~A}$ and $\mathrm{B}$ : Occlusal $(\mathrm{A})$ and intra-oral; $(\mathrm{B})$ views of the definitive prostheses

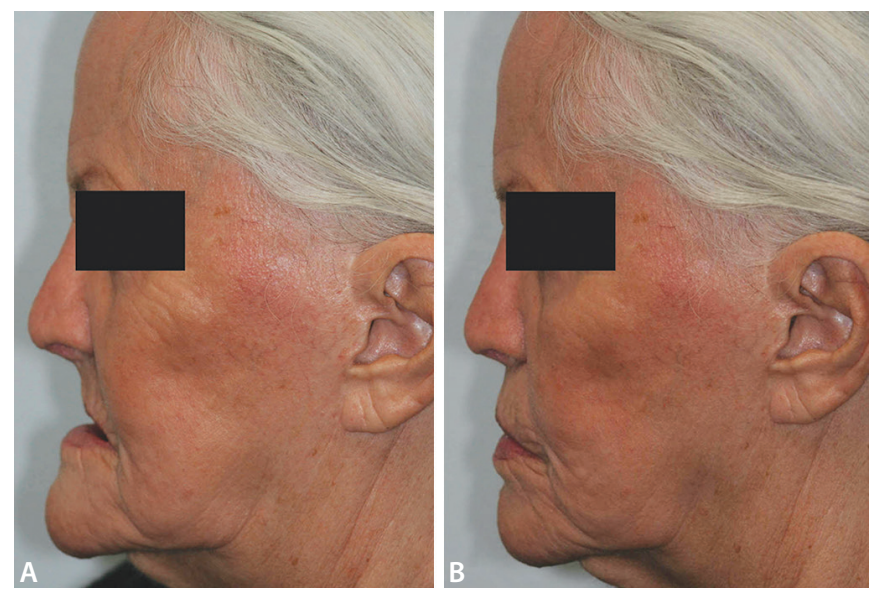

Figs 7A and B: Lateral views of the patient before (A) and after; (B) both prostheses were inserted

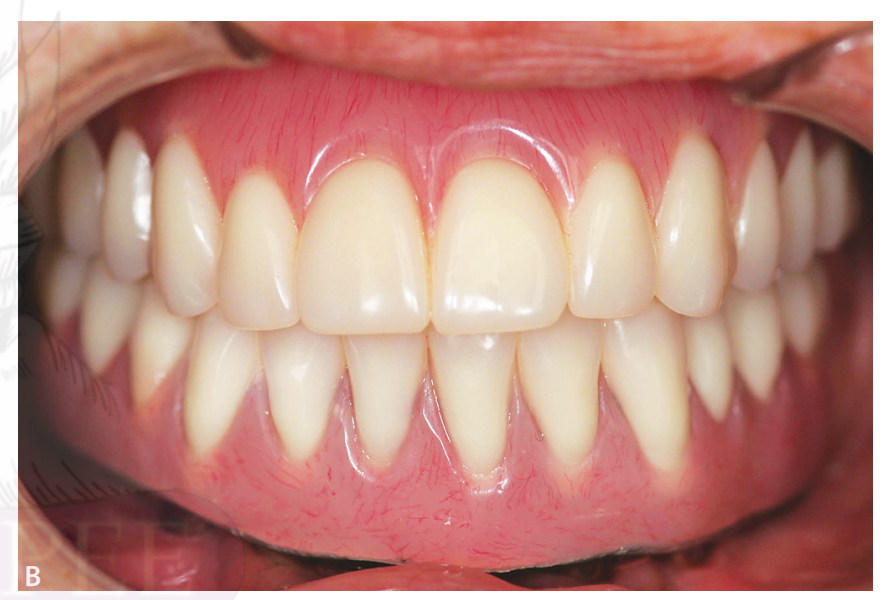

and then screwed on the implants in the clinic (Figs 6 and 7). The patient was followed up for two years and no major complications with the implants and prostheses were observed (Fig. 8).

\section{Discussion}

Computer-guided implant placement by using the $C B C T$ imaging, 3D implant planning software and stereolithographic surgical guide
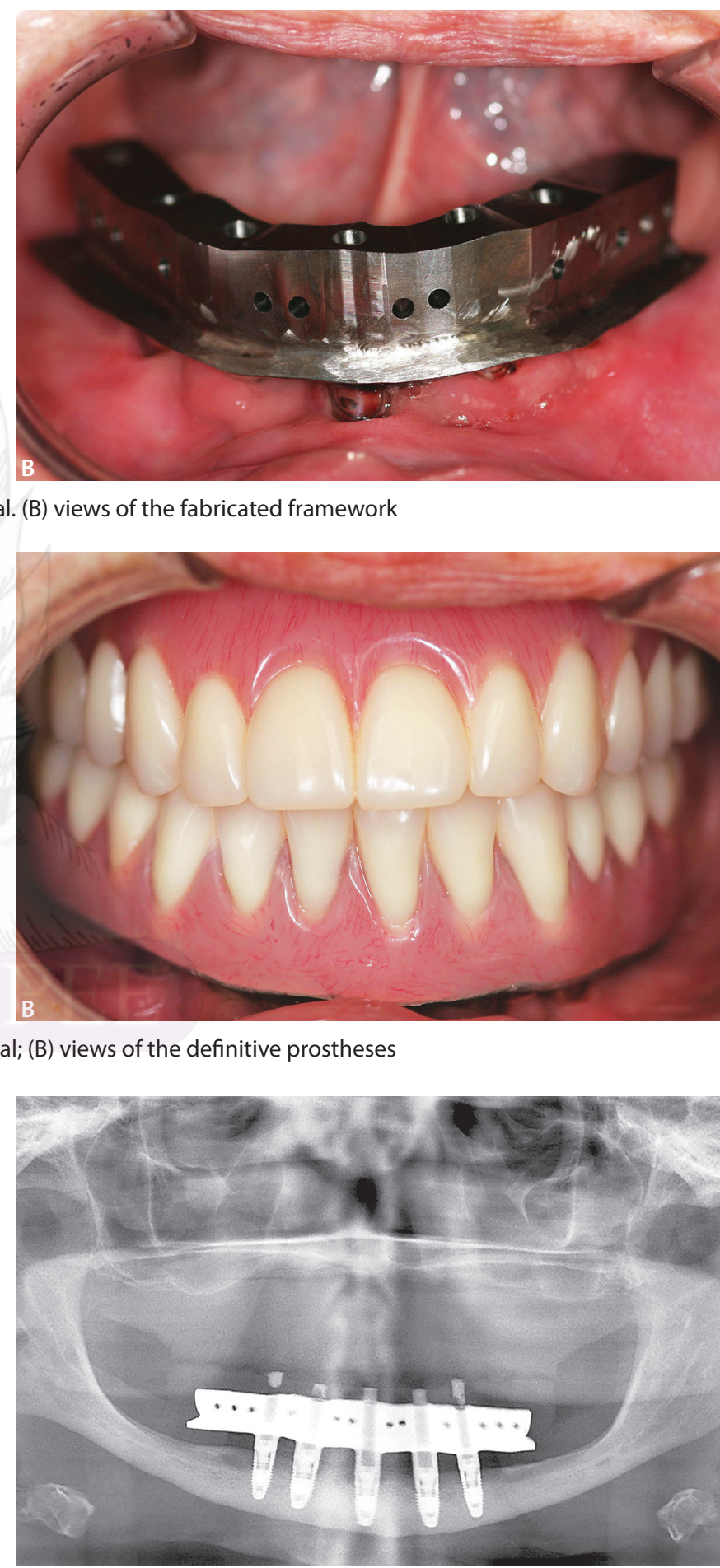

Fig. 8: Panoramic radiograph of the patient two years after implant placement. Note significant bone loss in the posterior mandible and the location of both mental foramina and inferior alveolar nerve 
has recently become a viable treatment option. ${ }^{4,5}$ Stereolithography is an additive manufacturing procedure that works by focusing an ultraviolet laser onto a vat of photopolymer resin. ${ }^{5}$ The ultraviolet laser is utilized to draw a previously-designed shape on to the surface of the photopolymer vat by means of a CAM/CAD software. Because photopolymers are sensitive to ultraviolet light, the resin is photochemically solidified and creates a single layer of the desired 3-dimensional object. This procedure is repeated for each layer of the design until the tangible 3 -dimensional object is complete. ${ }^{5}$

Computer-guided implant placement is a technique sensitive procedure. It includes a chain of diagnostic and therapeutic events, and the sum of errors throughout the computer-aided implant placement cascade causes a drop in accuracy. ${ }^{4}$ Certain levels of vertical and horizontal errors from the digital plan to the surgical field were reported, ${ }^{4}$ and major complications such as nerve injury may be caused by untrained and inexperienced clinicians.

In the dental literature, there are a few studies regarding implant placement by using CAD/CAM surgical guides. ${ }^{12-19}$ In an in vitro study by Turbush and coworkers, ${ }^{14} 150$ implants were inserted with three types of stereolithographic guides. They reported that the mean deviations in the linear distance were $1.18 \mathrm{~mm}$ at the implant neck and $1.44 \mathrm{~mm}$ at the implant apex for 150 implants. In a clinical study, Ozan and coworkers ${ }^{15}$ placed 110 implants by using stereolithographic guides. They noted that the mean linear deviations were $1.11 \pm 0.7 \mathrm{~mm}$ at the implant neck and $1.41 \pm 0.9 \mathrm{~mm}$ at the implant apex. They also observed that the angular deviations of the placed implants compared to the planned implants were $2.9,4.6$, and 4.5 degrees for the tooth-, bone-, and mucosa-supported surgical guides respectively.

Valente and coworkers ${ }^{17}$ investigated the clinical accuracy of computer-aided, template-guided oral implant surgery by comparing the three-dimensional positions of planned and placed implants. Twenty-five patients received 104 implants by using computerized tomography, software, and CAD/CAM surgical templates. In their study, 89 implants were available for accurate comparisons. They found that mean lateral deviations at the coronal and apical ends of the implants were $1.4 \mathrm{~mm}$ and $1.6 \mathrm{~mm}$, respectively. In addition, they noticed that the mean depth and angular deviations were $1.1 \mathrm{~mm}$ and 7.9 degrees. Vieira et al., ${ }^{18}$ evaluated the reliability and accuracy of a flapless computer-guided surgical method. They inserted 62 implants in 14 patients by means of stereolithographic surgical guides. When compared to the planned implants, the actual placed implants showed mean linear deviations at the cervical, middle, and apical implant sections of $2.17 \mathrm{~mm}, 2.32 \mathrm{~mm}$, and $2.86 \mathrm{~mm}$, for the maxilla; and $1.42 \mathrm{~mm}, 1.42 \mathrm{~mm}$, and $1.42 \mathrm{~mm}$ for the mandible, respectively. Although the previous reports regarding guided-implant placement indicated similar deviations, ${ }^{12-19}$ it should be kept in mind that implant placement without surgical guides (free-hand) is associated with greater deviations. ${ }^{9}$

A few previous studies have indicated that full-arch titanium frameworks milled by using CAD/CAM method fit better than the ones fabricated by using conventional prosthetic methods. ${ }^{20-24}$ Because CAD/CAM method eliminates several traditional prosthetic fabrication steps such, wax-up, metal casting and polishing that may cause inaccuracies in the final framework. ${ }^{20-24}$ In the present report, the full-arch CAD/CAM titanium framework fit accurately, and no adjustments were needed.

\section{Conclusion}

The technique depicted in this report may be used to restore severely resorbed edentulous arches in two days if it is executed by trained restorative dentists adhering to strict guidelines.

\section{Clinical significance}

Implants offer many alternative treatments to the edentulous patients that were not possible with traditional prosthetic methods. Digital technologies such as cone-beam computed-tomography, computer-aided design and computer-aided manufacturing, stereolithography, and 3D implant planning software are recently used to restore edentulous arches with promising outcomes in shorter periods.

\section{References}

1. Turkyilmaz I, Tozum TF, Fuhrmann DM, Tumer C. Seven-year follow-up results of TiUnite implants supporting mandibular overdentures: early versus delayed loading. Clin Implant Dent Relat Res 2012;14 Suppl 1:e83-90.

2. Turkyilmaz I, Tozum TF. 30-Year Outcomes of Dental Implants Supporting Mandibular Fixed Dental Prostheses: A Retrospective Review of 4 Cases. Implant Dent 2015;24:620-624.

3. Turkyilmaz I, Company AM, McGlumphy EA. Should edentulous patients be constrained to removable complete dentures? The use of dental implants to improve the quality of life for edentulous patients. Gerodontology. 2010;27:3-10

4. Ozan O, Orhan K, Turkyilmaz I. Correlation between bone density and angular deviation of implants placed using CT-generated surgical guides. J Craniofac Surg 2011;22:1755-1761.

5. Cushen SE, Turkyilmaz I. Impact of operator experience on the accuracy of implant placement with stereolithographic surgical templates: an in vitro study. J Prosthet Dent 2013;109:248-254.

6. Abduo J. Fit of CAD/CAM implant frameworks: a comprehensive review. J Oral Implantol 2014;40:758-766.

7. Faeghinejad M, Proussaefs P, AlHelal A, Lozada J. The CAD/CAM Compound Prosthesis: Digital Workflow for Fabricating CementRetained Zirconia Prosthesis Over Screw-Retained Milled Titanium Bars. Int J Periodontics Restorative Dent. 2019;39:39-47

8. Apostolakis D, Kourakis G. CAD/CAM implant surgical guides: maximum errors in implant positioning attributable to the properties of the metal sleeve/osteotomy drill combination. Int J Implant Dent. 2018;4:34.

9. Reyes A, Turkyilmaz I, Prihoda TJ. Accuracy of surgical guides made from conventional and a combination of digital scanning and rapid prototyping techniques. J Prosthet Dent. 2015;113:295-303.

10. Laederach V, Mukaddam K, Payer M, Filippi A, Kuhl S. Deviations of different systems for guided implant surgery. Clin Oral Implants Res. 2017;28:1147-1151.

11. Rungcharassaeng K, Caruso JM, Kan JY, Schutyser F, Boumans T. Accuracy of computer-guided surgery: A comparison of operator experience. J Prosthet Dent. 2015;114:407-413.

12. Zhou W, Liu Z, Song L, Kuo CL, Shafer DM. Clinical Factors Affecting the Accuracy of Guided Implant Surgery-A Systematic Review and Meta-analysis. J Evid Based Dent Pract 2018;18:28-40.

13. Cassetta M, Di Mambro A, Giansanti M, Stefanelli LV, Cavallini C. The intrinsic error of a stereolithographic surgical template in implant guided surgery. Int J Oral Maxillofac Surg 2013;42:264-275.

14. Turbush SK, Turkyilmaz I. Accuracy of three different types of stereolithographic surgical guide in implant placement: an in vitro study. J Prosthet Dent. 2012;108:181-188.

15. Ozan O, Turkyilmaz I, Ersoy AE, McGlumphy EA, Rosenstiel SF. Clinical accuracy of 3 different types of computed tomography-derived stereolithographic surgical guides in implant placement. J Oral Maxillofac Surg. 2009;67:394-401.

16. Lopes A, Malo P, de Araujo Nobre M, Sanchez-Fernandez E. The NobelGuide ${ }^{\circledR}$ All-on- $4^{\circledR}$ Treatment Concept for Rehabilitation of Edentulous Jaws: A Prospective Report on Medium- and Long-Term Outcomes. Clin Implant Dent Relat Res. 2015;17 Suppl 2:e406-416.

17. Valente F, Schiroli G, Sbrenna A. Accuracy of computer-aided oral implant surgery: a clinical and radiographic study. Int J Oral Maxillofac Implants. 2009;24:234-242.

18. Vieira DM, Sotto-Maior BS, Barros CA, Reis ES, Francischone CE. Clinical accuracy of flapless computer-guided surgery for implant placement 
in edentulous arches. Int J Oral Maxillofac Implants. 2013;28:13471351.

19. Van Assche N, van Steenberghe D, Quirynen M, Jacobs R. Accuracy assessment of computer-assisted flapless implant placement in partial edentulism. J Clin Periodontol. 2010;37:398-403.

20. Ortorp A, Jemt T, Back T, Jalevik T. Comparisons of precision of fit between cast and CNC-milled titanium implant frameworks for the edentulous mandible. Int J Prosthodont. 2003;16:194-200.

21. Takahashi T, Gunne J. Fit of implant frameworks: an in vitro comparison between two fabrication techniques. J Prosthet Dent. 2003;89:256-60.
22. Katsoulis J, Mericske-Stern R, Enkling N, Katsoulis K, Blatz MB. In vitro precision of fit of computer-aided designed and computer-aided manufactured titanium screw-retained fixed dental prostheses before and after ceramic veneering. Clin Oral Implants Res. 2015;26:44-49.

23. Almasri R, Drago CJ, Siegel SC, Hardigan PC. Volumetric misfit in CAD/ CAM and cast implant frameworks: a university laboratory study. J Prosthodont. 2011;20:267-274.

24. Abduo J, Lyons K, Bennani V, Waddell N, Swain M. Fit of screwretained fixed implant frameworks fabricated by different methods: a systematic review. Int J Prosthodont. 2011;24:207-220. 